\title{
MANAGEMENT DECISIONS - REALIZATION AND ASSESSMENT
}

\author{
L. Stankova* \\ University of National and World Economy, Sofia, Bulgaria
}

\begin{abstract}
Modern organizations operate in conditions of an extremely dynamic and competitive market, of permanently changing technologies and constantly increasing requirements. As a result of this turbulence of the environment, managers are challenged to constantly take quick, adequate and creative decisions. On one hand, decision-making is considered a daily and required task for managers, since it is related to the performance of each of their managerial functions. On the other hand, this process may be discussed also as a tool for increasing the organizational efficiency due to the fact that improving managers' decision-making skills leads to a more successful realization of the objectives and tasks of the organization. One of the ways for improving managers' decision-making skills includes analyzing, summarizing experience and drawing out good practices, based on the decisions made. Therefore, this paper summarizes the different stages of the decision-making process (acknowledging the problem, problem diagnostics, formulation of restrictions, identification of the criteria for choosing a decision, generation of alternatives, assessment of alternatives, choosing an alternative, realization, assessment of the decision and summary of the accumulated experience) and the last three stages of the process are discussed in more details.
\end{abstract}

Key words: decision-making process, decision implementation, effectiveness of the decisions

\section{INTRODUCTION}

The principles, models, and approaches to making management decisions hold an important place in management science and practice. One of the main reasons for this is the fact that each organizational system is a result of the decision-making process that takes place within it. Each stage of the management process requires making timely, effective and adequate decisions by the managers. Making management decisions turns out to be a major and extremely responsible task for each manager since, on one hand, it integrates and becomes a basis for realization of each managerial function, and on the other hand, the result of the decision made affects all participants and aspects of the management activity, and hence it affects the competitive power of the organization in general. This is why we could imply that to manage means to constantly make decisions - first, to make decisions to identify the objectives of the organization and second, to make decisions on how the available resources could most effectively and efficiently be used for

\footnotetext{
${ }^{*}$ Correspondence to: Lilyana Stankova, University of National and World Economy, Sofia 1700, tel.+35928195428,e-mail: l_stankova@unwe.bg
}

achieving the set objectives. In this connection the paper focuses on the role of the action plan for the successful implementation of the decisions made. There are directions drawn out on how to prepare an action plan and how to use the action plan as a basis for efficient control. Based on deducted key characteristics of the efficient management decisions, a check list is prepared, which could be used by managers both for assessing the decisions already made and for identifying the fields for improving and developing their skills for this process.

\section{DECISION-MAKING PROCESS}

Making the management decision is a "process of selecting a course of action from a set of alternatives" (1) and the main goal of this process is achieving the objectives and tasks of the organization at optimum distribution and use of the available resources. Making management decisions could be also defined as "a central pivot for the organization's life" (2) because in many cases the future and success of the particular organization depends on the decisions, made by the managers.

The process of forming a management decision has an intuitive, logical or rational nature. 
Intuitive decisions are a choice based on the feeling that this is the right choice. Decisions based on logic are a choice, determined by the knowledge or the accumulated experience of the person, who makes them. Logic, as a basis for forming a management decision, is useful mainly in situations that tend to frequently recur in the organization. In complex situations, the manager's logical ratiocinations may turn out to be insufficient, especially when there are many factors to be considered and the manager is unable to cover them all. Rational decisions, on the other hand, differ from intuitive decisions and decisions, based on logic, in the fact that they depend on the manager's past experience. They are based on an algorithm, called a decision-making process. The decision-making process is divided in "several interconnected stages, depending on the degree of programmability of the decision, the manager's management style and the selected methodology". (1)

There are different opinions on the stages and phases of the process. This is only logical since the decisions that have to be made are various in nature, complexity and significance. There is a specific way of making decision for each particular problem. Nevertheless, there is a certain order in developing each decision, irrespective of its specific features and characteristics. In the procedure of making and implementing the decision, several stages could be outlined. Although different researchers and specialists define them in a different way, there is still certain similarity in the content of each one of them.

Once we have introduced the different classifications of the decision-making process, we could define one optimum option to include the stages that are most frequently indicated by authors (1-9). The different stages of the summarized decision-making model that we offer are:

- acknowledging the problem - the need of making a decision could manifest either as a problem, which occurs when the outcomes do not match the set objectives, or as an opportunity, when managers see potential for optimization of the organizations' activity;

- problem diagnostics - identification and study of the main reasons that lead to occurrence of the problematic situation;

- formulation of restrictions - the identification of restrictions, which could vary depending on the situation and the individual preferences of different managers, is a prerequisite for proper formulation of alternatives for a decision and for selection of the optimum alternative;

- identification of criteria - the identified criteria should be applicable as quantitative measurers for comparing alternatives; apart from identification, the criteria sometimes need to be arranged in terms of importance or each criterion needs to be given certain significance;

- generation of alternatives - this stage includes development of options for alternative decisions;

- assessment of alternatives - here comes identification of the strengths and weaknesses of each defined alternative, which will consequently lead to selection of the optimum alternative;

- choosing an alternative - here, managers choose which alternative to be applied in practice and they need to choose the best alternative not only in terms of indicators but they also need to choose the alternative which provides the greatest opportunity for practical realization;

- realization - it is important whether managers will succeed in transforming the ideas of the selected alternative into effective practical actions;

- assessment of the decision - at this stage, managers analyze the information about the way the decision is being implemented whether the problem is solved and whether the decision is effective in terms of achieving the set objectives;

- summary of the accumulated experience this includes analyses and summary of the accumulated experience and defining the good practices for making management decisions in future.

\section{REALIZATION OF THE MANAGEMENT DECISION}

The implementation of the management decision is a plan for ensuring, directing and using the resources provided for its realization. This plan comprises all required instructions and details for achieving the set objectives as well as information, needed for coordinating all actions for realization of the decision. The main methods, used for realization of management decisions, are the methods for planning, organization and control over the implementation of the decision made, as illustrated in Figure 1. (10) 


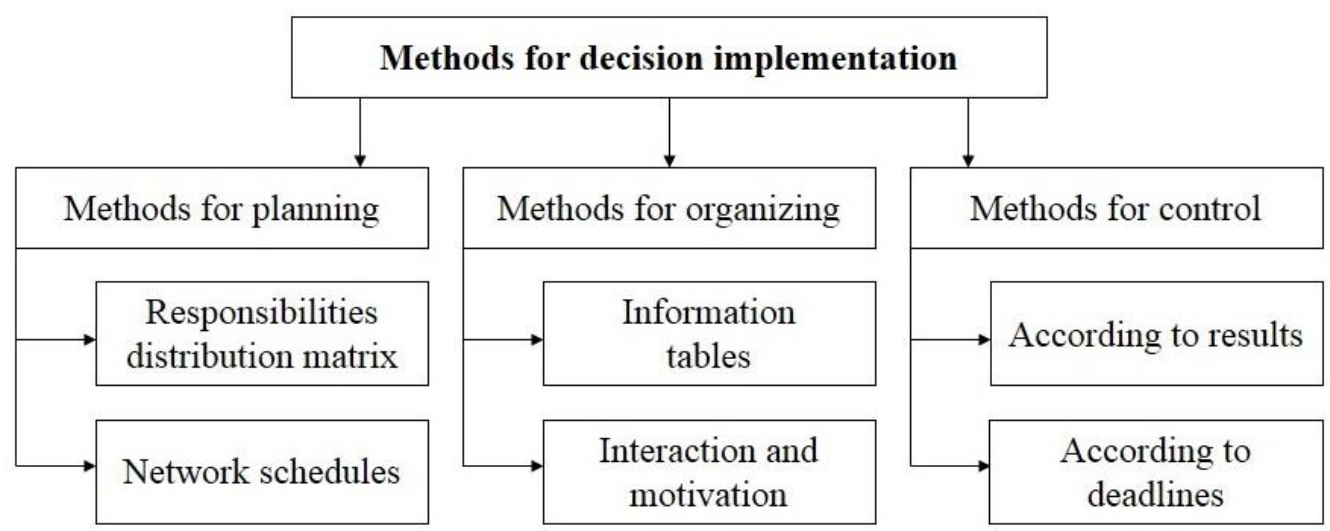

Figure 1. Classification of methods for decision implementation L. Trofimova, 2011

Methods for planning. For drafting the plan for realization of the management decision, first the following elements need to be determined: the particular implementers of the decisions; the planned deadlines for development and implementation of the decision; clear instructions to the people, involved in the realization of the decision; a diagram of the interaction and of the hierarchical levels in the organization; system for motivating the people, involved in the implementation of the decision, etc. The plan for realization of the decision specifies who, what, where, with what, how, and when has to be done. The answers to these questions must be documented. The main methods used for drafting the plan for realization of management decisions are: distribution of the responsibilities and use of network schedules.

Planning of the distribution of the responsibilities, rights and obligations for implementation of the decisions is formed in a matrix for distribution of responsibilities. This matrix represents a table, which comprises a list of the tasks, required for the realization of the decision, all particular actions, included in the implementation of the tasks, as well as the people in charge of each particular task - their names, positions and the structural units they belong to. (Figure 2)

\begin{tabular}{|l|l|l|}
\hline \multicolumn{1}{|c|}{ Tasks } & \multicolumn{1}{|c|}{ Actions for task implementation } & $\begin{array}{c}\text { Person in charge } \\
\text { (name, position, } \\
\text { department) }\end{array}$ \\
\hline 1. & 1.1. & \\
\hline 2. & 1.2. & \\
\hline & 2.1. & \\
\hline
\end{tabular}

Figure 2. Sample matrix for distribution of responsibilities

The network schedule allows analyzing the activities and their interconnections. The main elements of the network schedule are activity, event and people in charge. Activity is a major task that needs to be implemented for the purposes of realization of the decision. Activities are expressed with lines and is it accepted that network schedules are developed in such a way as that time flows from the left to the right. The length of the lines does not correspond with the duration of the activities. The starting and end points of each activity are called events, usually marked with circles. The main difference between activities and events is that activities imply passing of time, while events are moments in time (Figure 3). (1)

Methods for organizing. The development of an information table for realization of the decisions and methods for influence and motivation are also included in the methods for organization of decision implementation. Management decisions are based on information, and documents are carriers of information. Therefore, in the process of realization of management decisions, the result of each operation must be strictly defined in the form of official documents. 


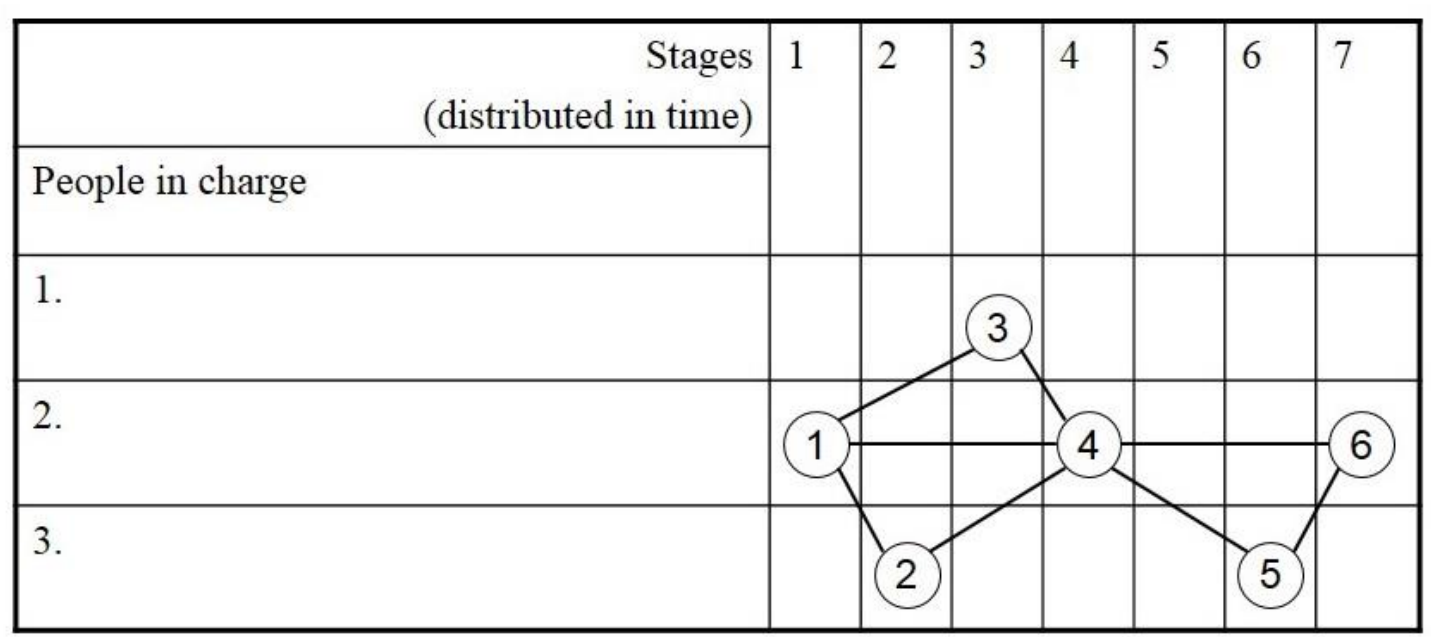

Figure 3 Sample scheme of a network schedule

The information table for decision realization is developed based on the table for distribution of responsibilities and it is supplemented with information about the type and form of the required documents that represent a result of the decisions made, particular deadlines, etc. (Figure 4) It is worth mentioning that coordination and control over implementation of the management decisions made is conducted based on this table.

\begin{tabular}{|l|l|l|l|l|l|l|l|}
\hline Tasks & $\begin{array}{c}\text { Actions for task } \\
\text { implementation }\end{array}$ & $\begin{array}{c}\text { Sources of } \\
\text { information, } \\
\text { required for task } \\
\text { implementation }\end{array}$ & $\begin{array}{c}\text { Required } \\
\text { resources for } \\
\text { task } \\
\text { implementation }\end{array}$ & $\begin{array}{c}\text { Task } \\
\text { implementers }\end{array}$ & $\begin{array}{c}\text { Document, } \\
\text { received as } \\
\text { a result of } \\
\text { the decision }\end{array}$ & $\begin{array}{c}\text { Document } \\
\text { users }\end{array}$ & $\begin{array}{c}\text { Deadline for } \\
\text { implementation }\end{array}$ \\
\hline 1. & $\begin{array}{l}1.1 . \\
1.2 .\end{array}$ & & & & & & \\
\hline 2. & $\begin{array}{l}2.1 . \\
2.2 .\end{array}$ & & & & & & \\
\hline
\end{tabular}

Figure 4. Sample information table for realization of decisions

The methods for influence and motivation are a reflection of the methods used for giving directions (oral or written) as well as of the material and non-material incentives used for motivation of the employees, involved in the realization of the decisions.

Methods for control. Realization of the decision made consists of implementing the selected alternative and conducting control for the purposes of achieving successful realization of the management decisions. Control includes provision of information about the results of the realization of the management decision, comparison of the actual results to the planned results and in case of deviations, taking the required corrective actions. The methods for control over the realization of the decision made are divided in control of the obtained results and control of the period for implementation.

Control of the obtained results represents an assessment of the achieved results and a comparison of these results to the planned ones, as well as consideration of the factors that facilitate or hinder their achievement. Therefore, the manager making the decision should very accurately determine the input and output of the management decisions, based on a clearly set and specific objective. The achieved results are compared to the expected ones and, in cases of deviations beyond the admissible limits, information about an occurred problem comes at the input of the management system, whereas the manager has to develop a new decision. This process is interactive and continues until the achieved results become equal to the planned results or 
until the objective is achieved. The main elements of control are objective (expected results), results (achieved results), measurers (comparison), conclusions (is the objective achieved), assessment of the factors that facilitate or hinder the realization of the management decision.

Control of the period for implementation is conducted as described above during presentation of the information tables for making management decisions and in this case it is being supervised whether the set deadlines are observed. Whenever possible, a reserve of time for implementation of the different tasks is provided for in the very beginning, and whenever this is not possible, either additional resources are used or deadlines are being extended.

\section{EFFECTIVENESS OF THE MANAGEMENT DECISION}

The effectiveness of the management decisions made in the organization largely depends on various factors. First, it is the environment, in which decisions are made, which "influences through economic, competitive, social, market, political, and technological factors and conditions". (12) Managers should foresee the possible results and different circumstances regarding the environment and these are usually classified as conditions of certainty, conditions of uncertainty, and conditions of risk.

Another important factor that affects the effectiveness of the decisions made is the manager's choice of an approach and style to be applied and the degree to which the manager chooses to attract and involve employees in the management decisionmaking process. In this connection, knowing major conceptions about the styles for management decision-making would allow each manager, on one hand, to identify and understand his/her own, preferred style of behavior with its strengths and weaknesses, and on the other hand, to get a general idea of the different styles, to see them from different perspectives, to better understand their advantages and to be able to correctly decide in which situations their application would be appropriate. Thus, a flexible, adaptive management style could be developed and maintained, which would allow growing of all strengths and worths of the manager's personality, at the same time conformable to the specifics of each particular task and situation.
The effectiveness of the decision is influenced mainly by the manager's personality, his/her competency and qualification, acquired management experience, his/her motivation and commitment to the work processes, etc. However, we should also consider the influence of the individuals, assisting the manager in the decision-making process, who are usually in charge of collecting information, determine the assessment criteria, conduct a preliminary assessment, process feedbacks, etc.

The ability of the manager to work with people, to accurately assess their abilities in distributing the tasks related to implementation of the decision as well as to guide their efforts in the proper direction and to motivate them, considering their individual needs and interests, also considerably influences the quality of the decisions made.

The organizational culture is another significant factor, which affects the efficiency of the management decisions made. It also depends on the factor time for solving the problem and sometime managers try to find a satisfactory decision due to lack of sufficient time. In such case, they optimize the quality of the decision under the criterion "timeliness". It is advisable to take into account some specifics of the decision-making teams, such as team integration - the degree, to which the team members wish to focus their efforts on solving the problem, intensity of their communications, their desire to reach an agreement; status of the team members profession, expertise, and experience, hierarchical level, age; opportunity to form coalitions - alliances of individuals for achieving control over the available resources, required for gaining supremacy in making a particular decision, etc. (7)

The question of what the effectiveness of the management decision made is and how it should be measured doesn't have a single answer. One of the possible approaches connects effectiveness of the management decisions to the achieved results. The application of this approach is related to identification of certain criteria for assessing the results of the decisions made as a correlation between the used resources and the achieved results or depending on the degree of achievement of a given objective.

Another approach equalizes the effectiveness of the management decision to its quality, which depends on some basic characteristics of the decision, such as validity, timeliness, 
feasibility, etc. Based on this approach, the purpose of this article is to offer a checklist to evaluate the decision-making process to assess whether it is likely to produce a good management decision.

A review of literature leads us to identification of the basic requirements to management decisions - target-oriented, validity, synergism, adaptability, hierarchical nature, feasibility, orientation, clarity, argumentation, controllability, period for implementation and timeliness. The questions below are developed based on these requirements. The questions could help managers assess the effectiveness of the decisions already made as well as identify the areas of their skills related to the process that could be improved and developed. For the purpose, managers have to answer conscientiously the following closed-ended question with "yes" or "no", and the questions answered negatively identify the problematic areas, which managers have to reconsider.

- Target-oriented

1. Does the decision made reflect the values of the organization?

2. Is the decision made focused on achieving the organizational objectives?

3. Does the decision made drive the organization closer to where it wants to be?

- Validity

4. Is the decision made at the time needed in the particular situation?

5. Was the information for the decisionmaking collected from all possible sources?

6. Is the decision made based on multiple ideals and different points of view?

7. Was there balance between facts and opinions at making the decision?

8. Were the possible reactions of the parties, interested in the decision made, taken into account?

- Synergy

9. Does the decision create synergy with other decisions made lately?

10. Is the decision in unison with other decisions made in the past?

- Adaptability

11. Does the decision take into account the changing environment?

12. Will the result of the decision be flexible in a changing environment?

- Hierarchical nature

13. Does the decision made comply with the rights, delegated to the manager?

- Feasibility

14. Are all required resources available for implementation of the decision?
15. Does the decision made consider the particular situation and the abilities and competences of the personnel?

- Orientation

16. Is it clear to whom the decision is oriented? Who/which units in the management system is/are subject of effect?

- Lucidity

17. Is the decision made formulated clearly and understandably for all interested parties?

18. Is the decision made properly understood by all employees, involved in its implementation?

- Argumentation

19. Is the necessity of the decision made clear? 20. Are the employees, involved in the implementation of the decision, clear as to how the results of it will affect their work, the work of their colleagues and the achievement of the organizational objectives in general?

- Controllability

21. Does the decision allow control over its implementation?

- Period for implementation

22. Are there clear deadlines for implementation of the decision made?

- Timeliness

23. Is the speed of making the decision optimum, from the time of its realization, development, and communication up to the organization of its implementation?

\section{CONCLUSIONS}

Management decisions are made for the purposes of ensuring targeted and successful functioning of organizations. Well-developed, timely made and effectively implemented decisions influence, guide and facilitate the activity and functioning of organizations. And vice versa, nothing will demotivate employees as much as ill-considered and hasty decisions, leading to useless efforts and resources, wasted in vain.

In conclusion, we could summarize that in order to be effective, all decisions made by managers should meet the following basic requirements:

- to be based on the strategic plan of the organization;

- to consider and be consistent with the complex and changing environment;

- to be based on various information from multiple sources with different points of view;

- to create energy in others and lead to successful actions.

\section{REFERENCES}

1. Aleksandrova, M., Upravlenski reshenia i risk, Sofia, 2009 (In Bulgarian) 
2. Harizanova, M., M. Mirchev, N. Mironova, Menidzhmant, Sofia, 2006 (In Bulgarian)

3. Litvak, B., Razrabotka upravlencheskogo reshenia, Moscow, 2000 (In Russian)

4. Prohorov, Yu., V. Frolov, Upravlencheskie reshenia, Saint Petersburg, 2011 (In Russian)

5. Vaughn, R., Decision Making and Problem Solving in Management, USA, 2007

6. Monahan, G., Management decision making, UK, 2000

7. Myuler, R., Upravlenski reshenia, Sofia, 1993 (In Bulgarian)
8. Smirnov, Э., Upravlencheskie reshenija, Moscow, 2001 (In Russian)

9. Jukaeva, V., E. Zubareva, V. Chuvikova, Prinjatie upravlencheskih reshenij, Moscow, 2012 (In Russian)

10.Trofimova, L., V. Trofimov, Upravlencheskie resheniJa (Metodы prinjatija i realizacii), Saint-Petersburg, 2011 (In Russian)

11.Andronov, E., M. Aleksandrova, Upravlenie na proekti, Sofia, 2006 (In Bulgarian)

12.Avramov, V., Liderstvo i menidzhmant, Sofia, 2003 (In Bulgarian) 